\title{
The Relationship Between Employee Empowerment and Subjective Wellbeing: Evidence from Services-Based SMEs in Pakistan
}

\section{Nimra Ali Khokher* and Abdul Raziq**}

\begin{abstract}
Employee empowerment plays a key role in the management of talented personnel: it enables an organization to use workers' skills and abilities in a way that enhances the performance of both employer and employee. Based on a survey of 349 small and medium enterprises in Quetta, this study examines the impact of employee empowerment on employees' subjective wellbeing, which is measured in terms of affective and cognitive components. Its results indicate that employee empowerment has a significant and positive impact on employees' subjective wellbeing, implying that senior managers should prioritize this aspect of human resource management.
\end{abstract}

Keywords: employee empowerment, subjective wellbeing, small or medium enterprise.

JEL classification: M12.

\section{Introduction}

With increased globalization and market competition, the concept of employee empowerment has gained considerable importance in human resource management. Committed, motivated employees are more likely to compete successfully and adapt more easily to organizational or market changes. Employee empowerment enables organizations to utilize talented personnel in a way that improves the performance of both employer and employee. In this context, it means giving employees more autonomy, but also greater responsibility and holding them accountable for the job-related decisions they make. It also means that senior managers may need to oversee the work of such employees because the latter can potentially influence the organization's output and performance.

\footnotetext{
MS student, Faculty of Management Sciences, Balochistan University of Information Technology, Engineering and Management Sciences, Quetta.

** Associate professor, Faculty of Management Sciences, Balochistan University of Information Technology, Engineering and Management Sciences, Quetta.
} 
Employee empowerment involves increasing a worker's authority, knowledge and motivation. In turn, this creates greater trust between the employee and the organization as well as among employees. Put more precisely, the extent of employee empowerment shapes employees' subjective wellbeing (SWB), which McGillivray and Clarke (2006) define as a "multidimensional evaluation of life, including cognitive judgments of life satisfaction and affective evaluations of emotions and moods" (p. 4). SWB therefore combines positive and negative affectivity - that is, pleasant and unpleasant emotions, respectively - as well as life satisfaction (Shmotkin, 1998). In this case, it enables one to measure the extent to which employees are happy or satisfied with their lives (see Page, 2005).

Not many studies have looked at the impact of employee empowerment on SWB. Studies such as Chikumbi (2011), Collings and Mellahi (2009), and Pinto and Dhulla (2012) have focused on its impact on employee satisfaction or the competitive advantage associated with employee empowerment and restricted their analysis to affective components (emotions and moods), rather than cognitive components. We aim to address this gap in the literature by gauging the impact of employee empowerment on both the cognitive and affective aspects of employees' SWB. The study draws on a sample of small and medium enterprises (SMEs) in Balochistan's services sector, for which there is little or no literature available since most other studies in this field tend to focus on larger firms in relatively developed regions.

In many countries, SMEs are an important part of the economy and contribute meaningfully to economic growth. However, the definition of an SME varies across countries, depending on the number of employees or the volume of revenue or assets. For example, Egypt defines an SME as employing between 5 and 50 workers, while Vietnam uses a range of 10 to 300 employees. The World Bank defines SMEs as firms with a maximum of 300 employees and US\$15 million apiece in annual revenues and assets. The Inter-American Development Bank describes SMEs as employing up to 100 workers and earning less than US\$3 million in revenues (Dahlberg Group, 2011, p. 6).

In Pakistan, the Small and Medium Enterprise Development Authority defines SMEs by the number of employees (up to 250), paid-up capital (up to PRs25 million) and annual sales (up to PRs250 million). The SME Bank uses the volume of assets as its sole criterion, while the Pakistan Bureau of Statistics considers only the number of employees. The State Bank of Pakistan defines an SME based on the nature of the business, the 
number of employees, the amount of capital and the value of annual net sales (Raziq \& Shaikh, 2015).

Our findings are expected to add to the literature on employee empowerment among SMEs in Balochistan and its impact on their employees' SWB. Effective employee empowerment gives firms a competitive advantage by enhancing workers' motivation, capacity for innovation and productivity.

\section{Literature Review and Hypotheses}

The concept of employee empowerment plays a crucial role in an organization's human resource management. Karakoc and Yilmaz (2009) note that empowered employees are better able to use their skills and abilities, which not only improves the performance of the organization, but also improves their own performance and working life. An important aspect of employee empowerment is the level of supervision this entails: Dizgah et al. (2011) argue that organizations that empower their employees must also supervise them and monitor their actions.

Empowering employees involves giving them a position of greater authority and the ability to influence the outcomes and events of the organization (Honold, 1997). Juhl et al. (1997) observe that it also entails building employees' work-related knowledge and motivation (p. 103). Empowering employees increases their level of satisfaction as a behavioral component of SWB, thereby increasing their commitment toward and engagement with the organization. This ultimately benefits the organization. Moreover, greater commitment and motivation among employees enables them to compete more successfully and adapt more easily to changes (Torani, Yazdi \& Gohari, 2008).

Employee empowerment is useful in that it improves the productivity of employees and allows the firm to make optimal use of their abilities by shaping their behaviors and emotions (Naderi, Jamshidiyan \& Salimi, 2008). As Seyedjavadin, Heydari and ShahbazMoradi (2009) show, the need to develop a more effective and productive workforce with high-caliber managerial capabilities requires organizations to empower their employees. Chikumbi (2011) adds that employee empowerment helps develop greater trust among employees and increases their sense of belonging to the organization. It gives employees a sense of motivation, satisfaction, commitment, authority, 
responsibility and accountability, thereby compelling the firm to achieve its goals in a better way (Ongori, 2009).

Based on the literature, we test the following hypotheses:

- H1: Employee empowerment has a significant positive impact on the affective components of employees' SWB.

- H2: Employee empowerment has a significant positive impact on the cognitive components of employees' SWB.

\section{Methodology}

This section describes the study's sampling method and SWB measures.

\subsection{Sampling Method}

The city of Quetta in Balochistan is not only a commercial hub, but also occupies a strategic position in the province. As the capital, Quetta has a far larger chain of businesses, industries, markets and resources than other cities in Balochistan, making it the best choice of sampling locations in the province. Moreover, limited or difficult access as well as time constraints meant it was not possible to sample SMEs in other cities in Balochistan.

We have used a nonprobability sampling method. It is worth noting that there is no dataset pertaining specifically to SMEs by province (Raziq \& Shaikh, 2015), much less one for Quetta alone. We have targeted SMEs in the services sector rather than in manufacturing because Quetta has far fewer manufacturing SMEs than the other provinces so that collecting data would not have been feasible.

The data collection procedure involved contacting the heads or managers of services sector firms in Quetta to establish if they qualified as an SME. In each case, we then asked to meet the head or manager and presented a letter explaining the purpose of the study and asking for permission to collect data. A total of 486 self-administered questionnaires ${ }^{1}$

\footnotetext{
${ }^{1}$ Each questionnaire introduced the researchers and the study's objectives. It also clarified that participation in the survey was voluntary and all responses strictly confidential. Only the supervisor and researcher had access to the completed questionnaires and all results were discussed with the supervisor alone.
} 
were distributed to SME employees, of which 380 were returned. Of these, 349 were deemed useable and the remaining were discarded.

\subsection{Measures of SWB}

The questionnaire for this study was adapted from Chikumbi (2011) and Jansen (2009). SWB can be measured by affective components such as positive or negative emotions, and by cognitive components such as life satisfaction. Both components were measured separately, using two different scales. Affective components (positive or negative emotions) were measured on a positive and negative affect scale. The scale comprised 20 items (emotions or feelings) and participants were asked to assess the extent to which each emotion or feeling applied to them. Of the 20 items, 10 measured positive affects and 10 measured negative affects against a five-point Likert scale ("strongly disagree, disagree, uncertain, agree, strongly agree"). The cognitive component, life satisfaction, was measured by a satisfaction-with-life scale comprising five items assessed against a five-point Likert scale ("strongly disagree, disagree, uncertain, agree, strongly agree").

To gauge the validity and reliability of the questionnaire, we asked a group of SME specialists and SME owners/managers in the services sector to assess its content against the prevailing culture, norms and environment of SMEs in Quetta. Based on their feedback, the questionnaire was revised, some irrelevant questions removed and certain questions rephrased for simplicity (see Appendix 1). The reliability analysis yielded a Cronbach's alpha coefficient greater than 0.7 .

\section{Results}

Table 1 provides descriptive statistics for the sample, indicating the distribution of respondents by age and gender. Almost two thirds of all respondents are male. Overall, most respondents are aged 15-35. 
Table 1: Descriptive statistics

\begin{tabular}{cllll}
\hline & Frequency & Percentage & $\begin{array}{c}\text { Valid } \\
\text { percentage }\end{array}$ & $\begin{array}{c}\text { Cumulative } \\
\text { percentage }\end{array}$ \\
\hline Gender & & & & \\
Male & 225 & 64.5 & 64.5 & 64.5 \\
Female & 124 & 35.5 & 35.5 & 100.0 \\
Total & 349 & 100.0 & 100.0 & \\
Age (years) & & & & \\
15-25 & 154 & 44.1 & 44.1 & 44.1 \\
26-35 & 123 & 35.2 & 35.2 & 79.4 \\
36-45 & 54 & 15.5 & 15.5 & 94.8 \\
$46-55$ & 11 & 3.2 & 3.2 & 98.0 \\
$56+$ & 7 & 2.0 & 2.0 & 100.0 \\
Total & 349 & 100.0 & 100.0 & \\
\hline
\end{tabular}

Note: $\mathrm{n}=349$.

Source: Authors' estimates.

\subsection{Exploratory Factor Analysis}

The factor analysis applied to all the scales used in the study reveals that the Kaiser-Meyer-Olkin value of each component is greater than 0.70, indicating its sampling adequacy. Applying Bartlett's test of sphericity to each component yields significant values at the 0.05 level. Table 2 presents a rotated component matrix of the factor loadings for each variable, showing which questions relate to which factor. In each case, the item has a high loading of more than 0.5 in its component (variable). 
Table 2: Rotated component matrix

\begin{tabular}{|c|c|c|c|c|}
\hline Item & EE & $\mathrm{CC}$ & $\begin{array}{c}\mathrm{AC} \\
(\mathrm{PA})\end{array}$ & $\begin{array}{c}\mathrm{AC} \\
\text { (NA) }\end{array}$ \\
\hline I contribute to determining my performance objectives. & 0.747 & & & \\
\hline $\begin{array}{l}\text { My manager provides clear guidance on how s/he } \\
\text { wants a certain assignment done. }\end{array}$ & 0.675 & & & \\
\hline My manager allows me to make job-related decisions. & 0.756 & & & \\
\hline $\begin{array}{l}\text { My manager allows me to innovate and take risks that } \\
\text { relate to new developments. }\end{array}$ & 0.769 & & & \\
\hline My job requires me to take initiative and responsibility. & 0.720 & & & \\
\hline In most ways, my life is close to ideal. & & 0.760 & & \\
\hline My life is in excellent condition. & & 0.832 & & \\
\hline I am satisfied with my life. & & 0.844 & & \\
\hline So far, I have gotten the important things I want in life. & & 0.682 & & \\
\hline I usually feel interest in life. & & & 0.983 & \\
\hline I usually feel excitement in life. & & & 0.978 & \\
\hline I usually feel strong in life. & & & 0.960 & \\
\hline I usually feel enthusiastic in life. & & & 0.964 & \\
\hline I usually feel proud in life. & & & 0.944 & \\
\hline I usually feel alert in life. & & & 0.965 & \\
\hline I usually feel inspired in life. & & & 0.578 & \\
\hline I usually feel determined in life. & & & 0.983 & \\
\hline I usually feel attentive in life. & & & 0.972 & \\
\hline I usually feel active in life. & & & 0.609 & \\
\hline I usually feel distressed in life. & & & & 0.995 \\
\hline I usually feel upset in life. & & & & 0.965 \\
\hline I usually feel guilty in life. & & & & 0.958 \\
\hline I usually feel scared in life. & & & & 0.961 \\
\hline I usually feel hostile in life. & & & & 0.971 \\
\hline I usually feel irritable in life. & & & & 0.979 \\
\hline I usually feel ashamed in life. & & & & 0.942 \\
\hline I usually feel nervous in life. & & & & 0.963 \\
\hline I usually feel jittery in life. & & & & 0.955 \\
\hline I usually feel afraid in life. & & & & 0.988 \\
\hline
\end{tabular}

Note: $\mathrm{EE}=$ employee empowerment, $\mathrm{CC}=$ cognitive component, $\mathrm{AC}=$ affective component, $\mathrm{PA}=$ positive affectivity, $\mathrm{NA}=$ negative affectivity.

Extracted method: principal component analysis.

Rotation method: varimax with Kaiser normalization. KMO test result $>0.5$. Bartlett's test result $=p<0.05$ (factor loadings of less than 0.5 are omitted).

Source: Authors' estimates. 


\subsection{Correlation Analysis}

Before performing a regression analysis to test the hypotheses, we examine the correlation between the variables, following Hair et al. (2010), to determine if it is possible to investigate the impact of employee empowerment on employee SWB. Table 3 indicates correlation between all the variables used in the study at a 5 percent level of significance. This implies that a regression analysis is feasible. Since the results also indicate that the negative affects variable of the affective components of employee SWB shows no significant correlation with the other variables, we discard this variable.

Table 3: Reliability analysis and correlations

\begin{tabular}{lllll}
\hline & \multicolumn{1}{c}{ EE } & \multicolumn{1}{c}{ AC (PA) } & AC (NA) & CC \\
\hline EE & $(0.785)$ & & & \\
AC (PA) & $0.511^{* *}$ & $(0.973)$ & & \\
AC (NA) & -0.015 & -0.033 & $(0.992)$ & \\
CC & $0.358^{* *}$ & $0.342^{* *}$ & -0.008 & $(0.764)$ \\
\hline
\end{tabular}

Note: $\mathrm{EE}=$ employee empowerment, $\mathrm{CC}=$ cognitive component, $\mathrm{AC}=$ affective component, $\mathrm{PA}=$ positive affectivity, $\mathrm{NA}=$ negative affectivity.

** = significant at 0.05 level (two-tailed). Cronbach's alpha coefficients for multi-item scales given in parentheses.

Source: Authors' estimates.

\subsection{Regression Analysis}

Having satisfied the basic assumptions of a regression analysis (see Appendix 2), we move onto determining the impact of the employee empowerment variable (EE) on the SWB variable. Both hypotheses are tested at a 5 percent level of significance.

The first hypothesis (H1) states that EE has a significant positive impact on the affective components of SWB. The R-squared term (0.261) and adjusted R-squared (0.259) in Table 4 indicate that EE explains about 26 percent of the variance in the positive affectivity of the affective components of SWB. The multiple correlation coefficient of $\mathrm{R}(0.511)$ is significant, with a p-value of less than $0.05(\mathrm{~F}(349)=122.700 ; p<0.05)$. EE therefore has a significant positive variance in the positive affectivity of the affective components of SWB. 
Evidence from Services-Based SMEs in Pakistan

Table 4: Regression of EE on affective components of SWB

\begin{tabular}{|c|c|c|c|c|c|}
\hline $\mathbf{R}$ & R squared & $\begin{array}{c}\text { Adjusted R } \\
\text { squared }\end{array}$ & SE of estimate & $\mathbf{F}$ & Sig. \\
\hline \multirow[t]{3}{*}{$0.511 \mathrm{a}$} & 0.261 & 0.259 & 0.95592 & 122.700 & 0.000 \\
\hline & \multicolumn{2}{|c|}{ Unstandardized coefficients } & $\begin{array}{l}\text { Standardized } \\
\text { coefficients }\end{array}$ & $\mathbf{t}$ & Sig. \\
\hline & B & SE & Beta & & \\
\hline (Constant) & 1.491 & 0.178 & & 8.395 & 0.000 \\
\hline EE & 0.868 & 0.078 & 0.511 & 11.077 & 0.000 \\
\hline
\end{tabular}

Note: $\mathrm{a}=$ predictor $($ constant), $\mathrm{EE}=$ employee empowerment, $\mathrm{b}=$ dependent variable (positive affectivity of affective components of SWB), SE = standard error.

Source: Authors' estimates.

The beta term (0.511) in Table 4 is significant $(\mathrm{t}(349)=11.077 ; p<$ $0.05)$, indicating that other variables apart from EE also contribute to determining the positive affectivity of the affective components of SWB. This implies that we can reject the null hypothesis of no significant positive impact on the affective components of SWB with respect to EE.

The second hypothesis (H2) states that EE has a significant positive impact on the cognitive components of employee SWB. Table 5 gives the results of the regression used to test this hypothesis. The R-squared (0.128) and adjusted R-squared (0.126) values indicate that EE explains about 13 percent of the variance in the cognitive components of SWB. The multiple correlation coefficient of $\mathrm{R}(0.358)$ is significant $(\mathrm{F}(349)=50.949 ; p<0.05)$, with a p-value of less than 0.05 . These results demonstrate that EE has a significant positive variance in the cognitive components of SWB.

Table 5: Regression of EE on cognitive components

\begin{tabular}{|c|c|c|c|c|c|}
\hline $\mathbf{R}$ & R squared & $\begin{array}{c}\text { Adjusted R } \\
\text { squared }\end{array}$ & SE of estimate & $\mathbf{F}$ & Sig. \\
\hline \multirow[t]{3}{*}{$0.358 \mathrm{a}$} & 0.128 & 0.126 & 0.63248 & 50.949 & 0.000 \\
\hline & \multicolumn{2}{|c|}{ Unstandardized coefficients } & $\begin{array}{l}\text { Standardized } \\
\text { coefficients }\end{array}$ & $\mathbf{t}$ & Sig. \\
\hline & B & SE & Beta & & \\
\hline (Constant) & 1.613 & 0.117 & & 13.732 & 0.000 \\
\hline $\mathrm{EE}$ & 0.370 & 0.052 & 0.358 & 7.138 & 0.000 \\
\hline
\end{tabular}

Note: $\mathrm{a}=$ predictor $($ constant), $\mathrm{EE}=$ employee empowerment, $\mathrm{b}=$ dependent variable (cognitive components of SWB), SE = standard error.

Source: Authors' estimates. 
The beta term $(0.358)$ is significant $(\mathrm{t}(349)=7.138 ; p<0.05)$ and we can reject the null hypothesis of no significant positive impact on the cognitive components of SWB with respect to EE.

\section{Discussion}

The purpose of this study is to investigate the impact of employee empowerment on employee SWB. Our results suggest that employee empowerment is correlated with the affective and cognitive components of employee SWB at a 0.05 level of significance. The literature divides SWB into cognitive components and affective components. The latter comprise positive and negative affects, such that an employee is subject to either positive affects or negative affects.

Our results support the literature to the extent that there is a significant, positive correlation between employee empowerment and the affective and cognitive components of employee SWB. However, the results also indicate an insignificant correlation with the negative affects of the affective components of employee SWB. We therefore discard the negative affects and test both hypotheses with respect to the positive affects of the affective components of SWB. The results show that employee empowerment has a significant, positive impact in predicting the affective components as well as cognitive components of employee SWB.

Our results imply that empowering employees helps develop greater trust among them and a sense of belonging to the organization. This is in line with Chikumbi's (2011) findings. Empowerment also leads to greater motivation, satisfaction, commitment, authority, responsibility and accountability, enabling the firm to achieve its goals more effectively (see Ongori, 2009). In this sense, employee empowerment has a significant positive impact on the SWB of a firm's employees.

\section{Conclusion}

This study examines the impact of employee empowerment on employee SWB for a sample of SMEs in the services sector in Quetta. It shows that employee empowerment plays a vital role in shaping the SWB of employees. Specifically, the study's results indicate that employee empowerment has a significant positive impact on the affective and cognitive components of employee SWB. 
These results have important implications for organizations, which stand to benefit from empowering their employees and according them greater authority and accountability. The increase in trust, sense of belonging, motivation and satisfaction that accompanies employee empowerment contributes to employees' SWB to a significant degree. The firm's managers are, therefore, responsible for ensuring that employee empowerment practices are implemented and monitored effectively, given the likely impact on the firm's success. This entails determining how best to empower and motivate talented employees, while ensuring that they feel their work is integral to the firm.

Future research could extend the study's hypotheses to SMEs in other sectors such as manufacturing as well as SMEs in other cities in Pakistan, depending on access, time and convenience. Given the dearth of research on employee empowerment and SWB in SMEs, the present study hopes to address this gap and to encourage further research in this area. Its findings are important to SME human resource managers, as they emphasize the value of investing in, and empowering, talented employees. 


\section{References}

Chikumbi, C. N. L. (2011). An investigation of talent management and staff retention at the Bank of Zambia. Unpublished Master's thesis, Nelson Mandela Metropolitan University, Port Elizabeth, South Africa.

Collings, D. G., \& Mellahi, K. (2009). Strategic talent management: A review and research agenda. Human Resource Management Review, 19(4), 304-313.

Dahlberg Group. (2011). Report on support to SMEs in developing countries through financial intermediaries. Geneva: Author.

Dizgah, M. R., Chegini, M. G., Farahbod, F., \& Kordabadi, S. S. (2011). Empowerment and organizational effectiveness in the executive organizations. Journal of Basic and Applied Scientific Research, 1(9), 973-980.

Hair, J. F., Black, W. C., Babin, B. J., \& Anderson, R. E. (2010). Multivariate data analysis (7th ed.). Upper Saddle River, NJ: Prentice Hall.

Honold, L. (1997). A review of the literature on employee empowerment. Empowerment in Organizations, 5(4), 202-212.

Jansen, R. C. (2009). An investigation into the subjective wellbeing of the female stripper. Unpublished Master's thesis, University of South Africa, Pretoria.

Juhl, H. J., Kristensen, K., Dahlgaard, J. J., \& Kanji, G. K. (1997). Empowerment and organizational structure. Total Quality Management, 8(1), 103-111.

Karakoc, N., \& Yilmaz, A. K. (2009). Employee empowerment and differentiation in companies: A literature review and research agenda. Enterprise Risk Management, 1(2), 1-12.

Keith, T. Z. (2006). Multiple regression and beyond. Boston, MA: Allyn \& Bacon.

McGillivray, M., \& Clarke, M. (2006). Human wellbeing: Concepts and measures. In M. McGillivray \& M. Clarke (eds.), Understanding human wellbeing (pp. 3-16). Tokyo: United Nations University Press. 
Naderi, N., Jamshidiyan, A. R., \& Salimi, Q. A. (2008). Employees' empowerment from on-jobs training, case study: Isfahan oil purge. Olome Ensani Va Ejtemaei, 7(27), 113-132.

Ongori, H. (2009). Managing behind the scenes: A viewpoint on employee empowerment. African Journal of Business Management, 3(1), 9-15.

Osbourne, J. W., \& Waters, E. (2002). Four assumptions of multiple regression that researchers should always test. Practical Assessment, Research and Evaluation, 8(2), 1-5.

Page, K. (2005). Subjective wellbeing in the workplace. Unpublished Bachelor's thesis, Deakin University, Faculty of Health and Behavioral Sciences, Melbourne, Australia.

Pinto, L. W., \& Dhulla, T. V. (2012). To study the talent management system in banking sector with regards to motivation and satisfaction. Bombay Psychologist, 27(1-2), 51-54.

Raziq, A., \& Shaikh, A. A. (2015). Exploring recruitment and selection practices in Pakistani SMEs. International Journal of Basic and Applied Sciences, 4(1), 102-108.

Seyedjavadin, S. R., Heydari, H., \& Shahbaz-Moradi, S. (2009). The effective factors on human resource empowerment in services, case study: Banks. Modiriyat Dolati, 1(2), 75-88.

Shmotkin, D. (1998). Declarative and differential aspects of subjective wellbeing and its implications for mental health in later life. In J. Lomranz (ed.), Handbook of aging and mental health: An integrative approach (pp. 15-43). New York: Plenum Press.

Torani, S., Yazdi, F. V., \& Gohari, M. R. (2008). The relationship between empowerment climate and employees' perception empowerment in training hospitals in Kerman. Modiriyate Salamt, 11(31), 17-26. 
Appendix 1

\section{Survey questionnaire}

\section{Section A: Biographical information}

\begin{tabular}{|l|l|l|l|l|l|}
\hline Gender & \multicolumn{5}{|l|}{} \\
\hline Designation & \multicolumn{5}{|l|}{} \\
\hline Division or department & \multicolumn{5}{|l|}{} \\
\hline Age (years) & $15-25$ & $26-35$ & $36-45$ & $46-55$ & $56+$ \\
\hline
\end{tabular}

\section{Section B: Talent management practices}

Talent management involves acquiring talent, managing employees' performance and salary packages, empowering employees and retaining talent.

Instructions: Please indicate the extent to which each statement applies to you, using the scale below.

\begin{tabular}{|c|c|c|c|c|}
\hline $\begin{array}{c}\text { Strongly } \\
\text { disagree }\end{array}$ & Disagree & Uncertain & Agree & Strongly agree \\
\hline 1 & 2 & 3 & 4 & 5 \\
\hline
\end{tabular}

\begin{tabular}{|l|l|l|l|l|l|l|}
\hline B1 & \multicolumn{1}{|c|}{ Acquiring talent } & & & & & \\
\hline 1 & $\begin{array}{l}\text { The firm conducts a skills audit to assess gaps in workers' } \\
\text { skills. }\end{array}$ & 1 & 2 & 3 & 4 & 5 \\
\hline 2 & $\begin{array}{l}\text { The recruitment process enables an extensive selection of } \\
\text { talent. }\end{array}$ & 1 & 2 & 3 & 4 & 5 \\
\hline 3 & $\begin{array}{l}\text { The recruitment process succeeds in selecting the best } \\
\text { talent. }\end{array}$ & 1 & 2 & 3 & 4 & 5 \\
\hline 4 & $\begin{array}{l}\text { The firm's induction programs are well structured and } \\
\text { help new employees settle in. }\end{array}$ & 1 & 2 & 3 & 4 & 5 \\
\hline 5 & $\begin{array}{l}\text { The firm has a large enough pool of managerial talent } \\
\text { available to fill any vacancies. }\end{array}$ & 1 & 2 & 3 & 4 & 5 \\
\hline 6 & $\begin{array}{l}\text { The firm has programs in place for building its pool of } \\
\text { managerial talent, from which it appoints new managers. }\end{array}$ & 1 & 2 & 3 & 4 & 5 \\
\hline 7 & $\begin{array}{l}\text { Before advertising a vacancy, the firm tries to tap its } \\
\text { internal talent pool. }\end{array}$ & 1 & 2 & 3 & 4 & 5 \\
\hline B2 & \multicolumn{1}{|c|}{ Performance management } & 1 & 2 & 3 & 4 & 5 \\
\hline 8 & $\begin{array}{l}\text { Targets and deadlines are clearly communicated to staff } \\
\text { members. }\end{array}$ & 1 & \multicolumn{1}{|c|}{} \\
\hline
\end{tabular}


The Relationship Between Employee Empowerment and Subjective Wellbeing:

Evidence from Services-Based SMEs in Pakistan

\begin{tabular}{|c|c|c|c|c|c|c|}
\hline 9 & $\begin{array}{l}\text { The firm's performance review focuses on evaluating my } \\
\text { competencies and abilities. }\end{array}$ & 1 & 2 & 3 & 4 & 5 \\
\hline 10 & I receive positive feedback in my performance appraisal. & 1 & 2 & 3 & 4 & 5 \\
\hline 11 & $\begin{array}{l}\text { My performance appraisal is discussed with my } \\
\text { supervisor. }\end{array}$ & 1 & 2 & 3 & 4 & 5 \\
\hline 12 & $\begin{array}{l}\text { Any weaknesses detected in the appraisal are addressed } \\
\text { through training as a staff development initiative. }\end{array}$ & 1 & 2 & 3 & 4 & 5 \\
\hline 13 & The firm conducts performance reviews regularly. & 1 & 2 & 3 & 4 & 5 \\
\hline 14 & $\begin{array}{l}\text { My personal objectives are aligned with the firm's } \\
\text { business goals. }\end{array}$ & 1 & 2 & 3 & 4 & 5 \\
\hline B3 & Salary packages & & & & & \\
\hline 15 & My salary package is adequate, given my (skill) level. & 1 & 2 & 3 & 4 & 5 \\
\hline 16 & $\begin{array}{l}\text { My salary and other variable payments compare well with } \\
\text { the rest of the market. }\end{array}$ & 1 & 2 & 3 & 4 & 5 \\
\hline 17 & My remuneration package is attractive. & 1 & 2 & 3 & 4 & 5 \\
\hline 18 & $\begin{array}{l}\text { My remuneration package matches the effort I put into my } \\
\text { work. }\end{array}$ & 1 & 2 & 3 & 4 & 5 \\
\hline 19 & $\begin{array}{l}\text { The rewards offered by the firm motivate one to perform } \\
\text { better. }\end{array}$ & 1 & 2 & 3 & 4 & 5 \\
\hline 20 & There are incentives in place to perform well. & 1 & 2 & 3 & 4 & 5 \\
\hline 21 & I think the firm's reward system is equitable. & 1 & 2 & 3 & 4 & 5 \\
\hline 22 & Being rewarded for good performance is valuable. & 1 & 2 & 3 & 4 & 5 \\
\hline B4 & Employee empowerment & & & & & \\
\hline 23 & I contribute to determining my performance objectives. & 1 & 2 & 3 & 4 & 5 \\
\hline 24 & $\begin{array}{l}\text { My manager provides clear guidance on how s/he wants } \\
\text { a certain assignment carried out. }\end{array}$ & 1 & 2 & 3 & 4 & 5 \\
\hline 25 & $\begin{array}{l}\text { My manager allows me to make decisions pertaining to } \\
\text { my job. }\end{array}$ & 1 & 2 & 3 & 4 & 5 \\
\hline 26 & $\begin{array}{l}\text { My manager allows me to be innovative and take risks } \\
\text { that relate to new developments. }\end{array}$ & 1 & 2 & 3 & 4 & 5 \\
\hline 27 & $\begin{array}{l}\text { The tasks I am assigned require me to take initiative and } \\
\text { responsibility. }\end{array}$ & 1 & 2 & 3 & 4 & 5 \\
\hline B5 & Retaining talent & & & & & \\
\hline 28 & The scope of my work is very interesting. & 1 & 2 & 3 & 4 & 5 \\
\hline 29 & The firm has a cordial atmosphere. & 1 & 2 & 3 & 4 & 5 \\
\hline 30 & My manager values my contribution to the firm. & 1 & 2 & 3 & 4 & 5 \\
\hline 31 & $\begin{array}{l}\text { I understand, and am committed to, the firm's vision and } \\
\text { goals. }\end{array}$ & 1 & 2 & 3 & 4 & 5 \\
\hline 32 & My job gives me satisfaction. & 1 & 2 & 3 & 4 & 5 \\
\hline 33 & My job is secure. & 1 & 2 & 3 & 4 & 5 \\
\hline 34 & The firm allows equal opportunities for promotion. & 1 & 2 & 3 & 4 & 5 \\
\hline 35 & My planned career path can be achieved at this firm. & 1 & 2 & 3 & 4 & 5 \\
\hline
\end{tabular}




\section{Section C: Subjective wellbeing}

SWB is measured using an affective component (a positive or negative affect) and a cognitive component (life satisfaction).

Instructions: Please indicate the extent to which each statement applies to you, using the scale below.

\begin{tabular}{|c|c|c|c|c|}
\hline $\begin{array}{c}\text { Strongly } \\
\text { disagree }\end{array}$ & Disagree & Uncertain & Agree & Strongly agree \\
\hline 1 & 2 & 3 & 4 & 5 \\
\hline
\end{tabular}

\begin{tabular}{|l|l|l|l|l|l|l|}
\hline C1 & \multicolumn{1}{|c|}{ Cognitive component: satisfaction with life } & & & & & \\
\hline 36 & In most ways, my life is close to ideal. & 1 & 2 & 3 & 4 & 5 \\
\hline 37 & My life is excellent. & 1 & 2 & 3 & 4 & 5 \\
\hline 38 & I am satisfied with life. & 1 & 2 & 3 & 4 & 5 \\
\hline 39 & So far, I have obtained the important things in life. & 1 & 2 & 3 & 4 & 5 \\
\hline 40 & If I could live my life over, I would change almost nothing. & 1 & 2 & 3 & 4 & 5 \\
\hline C2 & Affective component: positive or negative affectivity & & & & & \\
\hline 41 & I usually feel interested in life. & 1 & 2 & 3 & 4 & 5 \\
\hline 42 & I usually feel excited about life. & 1 & 2 & 3 & 4 & 5 \\
\hline 43 & I usually feel strong about life. & 1 & 2 & 3 & 4 & 5 \\
\hline 44 & I usually feel enthusiastic about life. & 1 & 2 & 3 & 4 & 5 \\
\hline 45 & I usually feel proud of my life. & 1 & 2 & 3 & 4 & 5 \\
\hline 46 & I usually feel alert. & 1 & 2 & 3 & 4 & 5 \\
\hline 47 & I usually feel inspired. & 1 & 2 & 3 & 4 & 5 \\
\hline 48 & I usually feel determined. & 1 & 2 & 3 & 4 & 5 \\
\hline 49 & I usually feel attentive. & 1 & 2 & 3 & 4 & 5 \\
\hline 50 & I usually feel active. & 1 & 2 & 3 & 4 & 5 \\
\hline 51 & I usually feel distressed. & 1 & 2 & 3 & 4 & 5 \\
\hline 52 & I usually feel upset. & 1 & 2 & 3 & 4 & 5 \\
\hline 53 & I usually feel guilty. & 1 & 2 & 3 & 4 & 5 \\
\hline 54 & I usually feel scared. & 1 & 2 & 3 & 4 & 5 \\
\hline 55 & I usually feel hostile. & 1 & 2 & 3 & 4 & 5 \\
\hline 56 & I usually feel irritable. & 1 & 2 & 3 & 4 & 5 \\
\hline 57 & I usually feel ashamed. & 1 & 2 & 3 & 4 & 5 \\
\hline 58 & I usually feel nervous. & 1 & 2 & 3 & 4 & 5 \\
\hline 59 & I usually feel jittery. & 1 & 2 & 3 & 4 & 5 \\
\hline 60 & I usually feel afraid. & 1 & 2 & 3 & 4 & 5 \\
\hline & & & & \\
\hline
\end{tabular}




\section{Appendix 2}

\section{Assumptions of multiple regression analysis}

\section{Linearity}

The assumption of linearity is important in regression analysis because the results obtained are based on this (Keith, 2006). If there is no linear relationship between the dependent and independent variables, then the regression results will either underestimate or overestimate the relationship (Osbourne \& Waters, 2002). Figure A1 indicates a linear relationship between the dependent and independent variables in this study, implying that the data used satisfies the assumption of linearity.

\section{Figure A1: Linearity between dependent and independent variables}

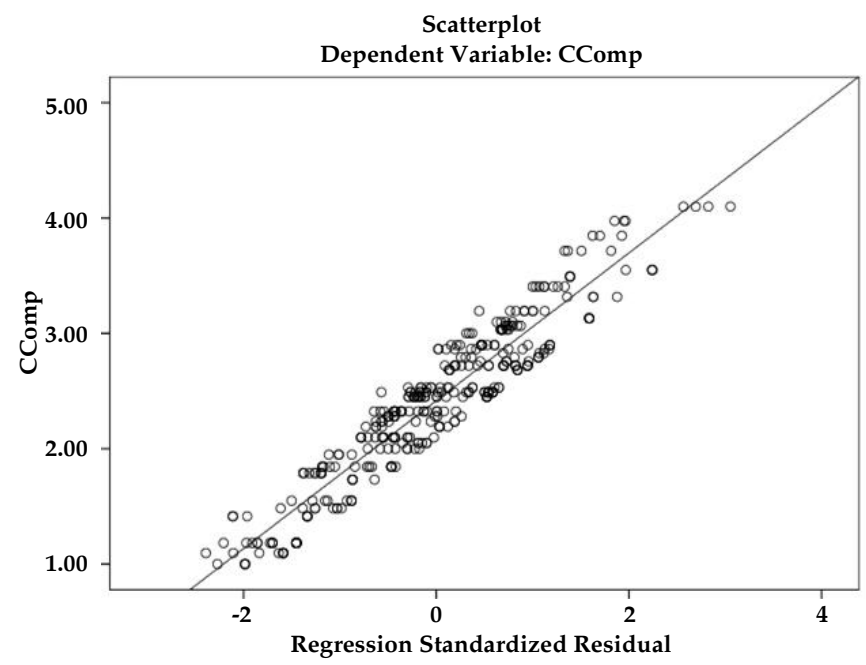

Source: Authors' estimates.

\section{Normality}

For a regression analysis, the data should be normally distributed. This is checked using different methods, including skewness and kurtosis statistics, histograms and p-plots. Table A1 indicates the normal distribution of the data used in this study, based on the skewness and kurtosis statistics. 
Table A1: Normal distribution of data

\begin{tabular}{lllllll}
\hline & & & \multicolumn{2}{c}{ Skewness } & \multicolumn{2}{c}{ Kurtosis } \\
\cline { 5 - 7 } & \multicolumn{1}{c}{ Mean } & SD & \multicolumn{1}{c}{ Statistic } & \multicolumn{1}{c}{ SE } & \multicolumn{1}{c}{ Statistic } & \multicolumn{1}{c}{ SE } \\
\hline EE & 2.1696 & 0.65396 & 0.262 & 0.131 & -0.299 & 0.260 \\
CC & 2.4159 & 0.67635 & -0.030 & 0.131 & -0.183 & 0.260 \\
AC (PA) & 3.3736 & 1.11056 & -0.159 & 0.131 & 0.159 & 0.260 \\
AC (NA) & 23.6126 & 10.51699 & 0.258 & 0.131 & -0.982 & 0.260 \\
\hline
\end{tabular}

Note: $\mathrm{n}=349$.

$\mathrm{EE}=$ employee empowerment, $\mathrm{CC}=$ cognitive component, $\mathrm{AC}=$ affective component, $\mathrm{PA}=$ positive affectivity, $\mathrm{NA}=$ negative affectivity, $\mathrm{SD}=$ standard deviation, $\mathrm{SE}=$ standard error.

Source: Authors' estimates.

The shape of the histogram in Figure A2 and the p-plot in Figure A3 both represent a normal distribution, that is, the errors are normally distributed and the residual values are plotted as a normal curve. Therefore, the assumption of normality is not violated.

Figure A2: Normal distribution of data (histogram)

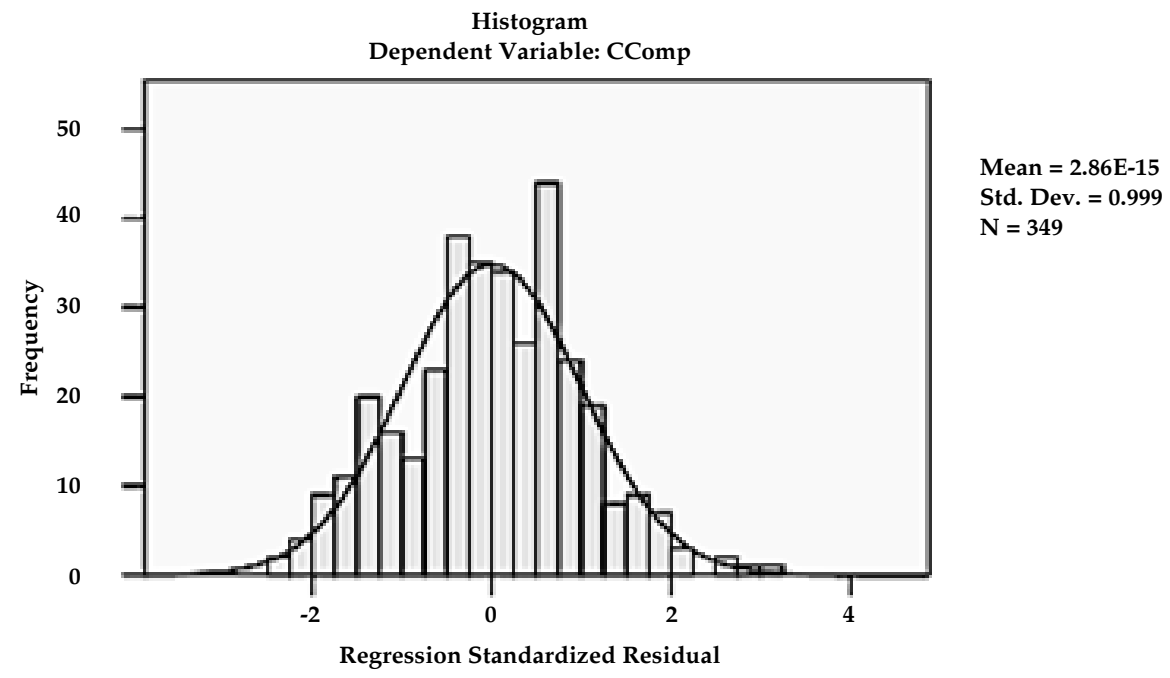

Source: Authors' estimates. 


\section{Figure A3: Normal distribution of data (probability plot)}

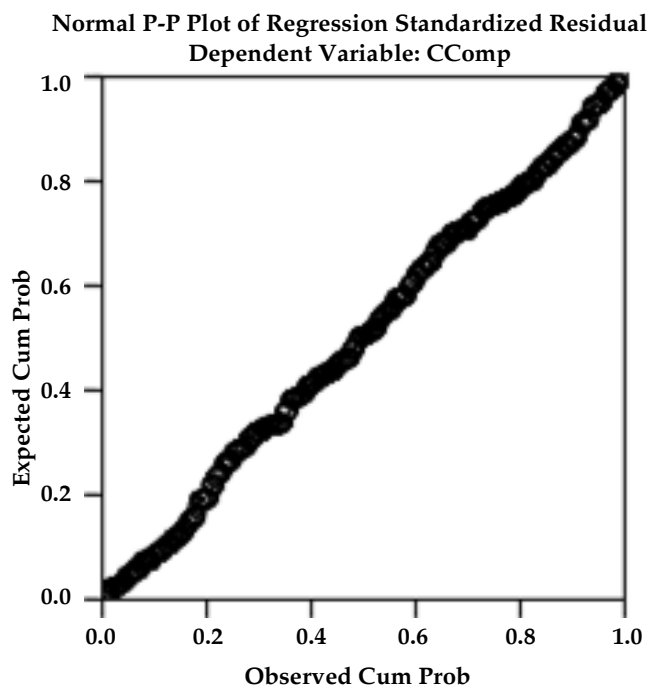

Source: Authors' estimates.

\section{Homoskedasticity}

In regression analysis, the assumption of homoskedasticity should be satisfied: there should be equal variance of errors across all levels of the independent variables. Figure A4 indicates that the errors are spread out consistently across the variables, implying that the data is homoskedastic.

\section{Figure A4: Homoskedasticity of independent variables}

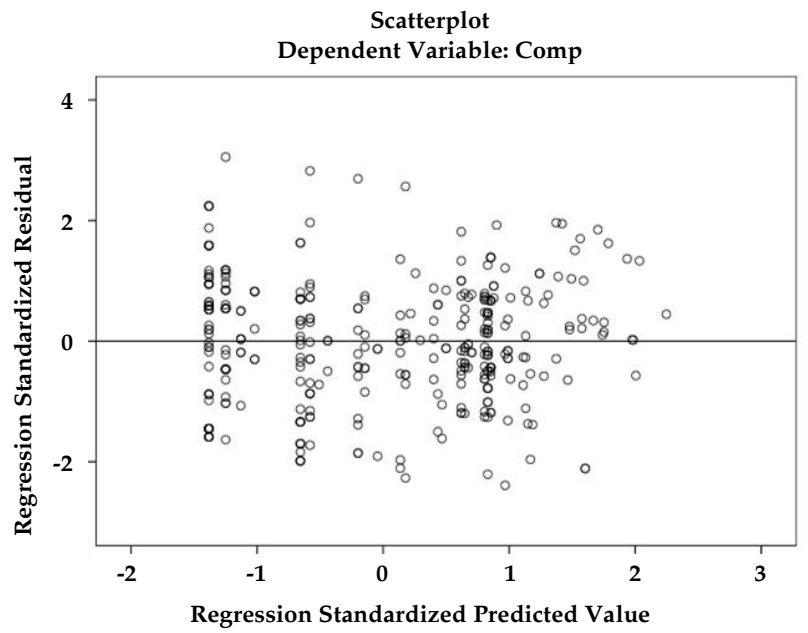

Source: Authors' estimates. 